\section{OP0168 A PHASE 2A, PLACEBO-CONTROLLED, RANDOMIZED STUDY OF ABT-981, AN ANTI-INTERLEUKIN-1ALPHA AND -1BETA DUAL VARIABLE DOMAIN IMMUNOGLOBULIN, TO TREAT EROSIVE HAND OSTEOARTHRITIS (EHOA)}

M. Kloppenburg ${ }^{1}$, C. Peterfy ${ }^{2}$, I.K. Haugen ${ }^{3}$, F. Kroon ${ }^{1}$, S. Chen ${ }^{4}$, L. Wang ${ }^{4}$ W. Liu ${ }^{4}$, G. Levy ${ }^{4}$, R. Fleischmann ${ }^{5}$, F. Berenbaum ${ }^{6}$, D. van der Heijde ${ }^{1}$, J. Medema ${ }^{4}$, M.C. Levesque ${ }^{4}{ }^{1}$ Leiden University Medical Center, Leiden, Netherlands: ${ }^{2}$ Spire Sciences, Inc., Boca Raton, FL, United States;

${ }^{3}$ Diakonhjemmet Hospital, Oslo, Norway; ${ }^{4}$ AbbVie Inc., North Chicago, IL ${ }^{5}$ University of Texas Southwestern Medical Center at Dallas, Metroplex Clinical Research Center, Dallas, TX, United States; ${ }^{6}$ University Pierre \& Marie Curie and Inserm, DHU i2B, APHP, Hospital Saint-Antoine, Paris, France

Background: No approved $O A$ therapies reduce pain and slow joint damage. Mouse data suggested that inhibiting IL- $1 \alpha$ and $-1 \beta$ with ABT-981 would reduce pain and slow structural progression in EHOA

Objectives: To test the efficacy and safety of ABT-981 in EHOA

Methods: Subjects with HOA per ACR criteria, $>3$ inflamed IP joints (tender, swollen, or both), hand pain $\geq 6$ (scale $0-10$ ), and $\geq 1$ erosive IP joint on X-ray (Verbruggen-Veys) were randomized to placebo (PBO) or ABT-981 $200 \mathrm{mg}$ SC every 2 wk for 26 wk. The primary outcome was AUSCAN hand pain at 16 wk. Subjects had radiographs of both hands and MRI of the index hand at baseline and 26 wk. Both radiographs (Verbruggen-Veys, GUSS TM, OARSI, Kellgren-Lawrence [KL]) and MRIs (HOAMRIS) were read by 2 independent central readers. A modified intent-to-treat population (ie, randomized and treated) was analyzed. Continuous efficacy endpoints were assessed using ANCOVA models with treatment and country as main factors and baseline measurements as covariates with LOCF imputation for the primary endpoint.

Results: Of 131 treated subjects ( $85 \%$ women; mean age 66 y), 61/67 randomized to PBO and 49/64 to ABT-981 completed the study; subject characteristics were well matched. AUSCAN pain was not significantly different vs PBO at wk 16 $(P=0.39$; Table 1 , Figure); $X$-ray data and other endpoints also were not statistically different vs PBO (Table 1). ABT-981 significantly decreased hsCRP, neutrophils, $\mathrm{IL}-1 \alpha$, and IL-1 $\beta$. Immunogenicity had no impact on ABT-981 pharmacokinetics. Besides injection site reactions and neutropenia, ABT-981 was well tolerated and safety was similar vs PBO, with no serious infections (Table 2).

Table 1

\begin{tabular}{|c|c|c|c|c|c|}
\hline & PBO & ABT-981 & PBO & ABT-981 & $P$ \\
\hline $1^{\circ}$ Endpoint & \multicolumn{2}{|c|}{$\begin{array}{l}\text { Baseline, } \\
\text { mean } \pm S D\end{array}$} & \multicolumn{3}{|c|}{$\begin{array}{c}\text { LS, } \\
\text { mean change } \pm S E \text { at Wk } 16\end{array}$} \\
\hline AUSCAN pain (0-50) & $39 \pm 7$ & $38 \pm 6$ & $-10.7 \pm 2.4$ & $-9.2 \pm 2.3$ & 0.39 \\
\hline $2^{\circ}$ Endpoints & \multicolumn{2}{|c|}{$\begin{array}{l}\text { Baseline, } \\
\text { mean } \pm S D\end{array}$} & \multicolumn{3}{|c|}{$\begin{array}{c}\text { LS, } \\
\text { mean change } \pm S E \text { at Wk } 26\end{array}$} \\
\hline AUSCAN function (0-90) & $69 \pm 15$ & $71 \pm 13$ & $-14.3 \pm 4.2$ & $-16.4 \pm 4.0$ & 0.49 \\
\hline Tender join & $12 \pm 6$ & $12 \pm 7$ & $-4.7 \pm 1.2$ & $-5.8 \pm 1.2$ & 0.32 \\
\hline Swolle & $6 \pm 6$ & $6 \pm 5$ & $-1.8 \pm 0.8$ & $-2.2 \pm 0.9$ & 0.64 \\
\hline$X$-ray erc & $2 \pm 2^{*}$ & $3 \pm 2^{*}$ & $0.26 \pm 0.08^{\dagger}$ & $0.18 \pm 0.08^{\dagger}$ & 0.33 \\
\hline $\mathrm{KL}$ score $(0-8$ & $41 \pm 13$ & $46 \pm 13$ & $0.13 \pm 0.19$ & $0.10 \pm 0.19$ & 0.87 \\
\hline OARSI JSI & & $32 \pm 9$ & $0.14 \pm 0$ & $0.03 \pm 0.19$ & 0.51 \\
\hline OARSI os & $23 \pm 11$ & $26 \pm 1$ & $0.25 \pm 0.15$ & $0.14 \pm 0.16$ & 0.45 \\
\hline HOAMRIS & $11 \pm 4$ & $10=$ & $0.92 \pm 0$ & $0.85 \pm$ & 0.89 \\
\hline HOAMRI & $18 \pm 9$ & $17 \pm 10$ & $0.26 \pm 0.64$ & $0.10 \pm 0.67$ & 0.80 \\
\hline HOAMRIS BML & $7 \pm 5$ & $5 \pm 4$ & $0.11 \pm 0.64$ & $0.44 \pm 0.66$ & 0.60 \\
\hline
\end{tabular}

Table 2

\begin{tabular}{lcc}
\hline & $\mathrm{PBO}(\mathrm{n}=67)$ & $\mathrm{ABT}-981(\mathrm{n}=64)$ \\
\hline Any AE/serious AE, \% & $88 / 3$ & $91 / 3$ \\
Death, \% & 0 & 0 \\
Infection/serious infection, \% & $51 / 0$ & $41 / 0$ \\
Injection site reaction, \% & 16 & 36 \\
Neutropenia by NCl CTCEE grade, $\mathrm{n}$ & 0 & 9 \\
G2 $\left(1000\right.$ to $\left.<1500 / \mathrm{mm}^{3}\right)$ & 0 & 3 \\
G3 $\left(500\right.$ to $\left.<1000 / \mathrm{mm}^{3}\right)$ & 0 & 0 \\
G4 $\left(<500 / \mathrm{mm}^{3}\right)$ & 0 & \\
\hline
\end{tabular}

Conclusions: Despite adequate pharmacodynamics results, targeting IL-1 may be ineffective in EHOA, as ABT-981 did not improve outcomes.

Acknowledgements: AbbVie funded the study (NCT02384538); participated in study design, data collection, analysis, and interpretation and in abstract writing, review, and approval; and funded writing support by M. Theisen of CPS.

Disclosure of Interest: M. Kloppenburg Grant/research support from: Pfizer, Consultant for: AbbVie, GlaxoSmithKline, Merck, Levicept, C. Peterfy Shareholder of: Spire Sciences, Inc. (which provides imaging services for clinical trials to multiple pharmaceutical companies), Employee of: Spire Sciences, Inc. (which provides imaging services for clinical trials to multiple pharmaceutical companies), Speakers bureau: Amgen, I. Haugen Consultant for: AbbVie, F. Kroon: None declared, S. Chen Shareholder of: AbbVie, Employee of: AbbVie, L. Wang Shareholder of: AbbVie, Employee of: AbbVie, W. Liu Shareholder of: AbbVie, Employee of: AbbVie, G. Levy Shareholder of: AbbVie, Employee of: AbbVie, R. Fleischmann Grant/research support from: AbbVie, Consultant for: AbbVie, F. Berenbaum Consultant for: AbbVie, Pfizer, Regeneron, D. van der Heijde Consultant for: AbbVie, Amgen, Astellas, AstraZeneca, BMS,

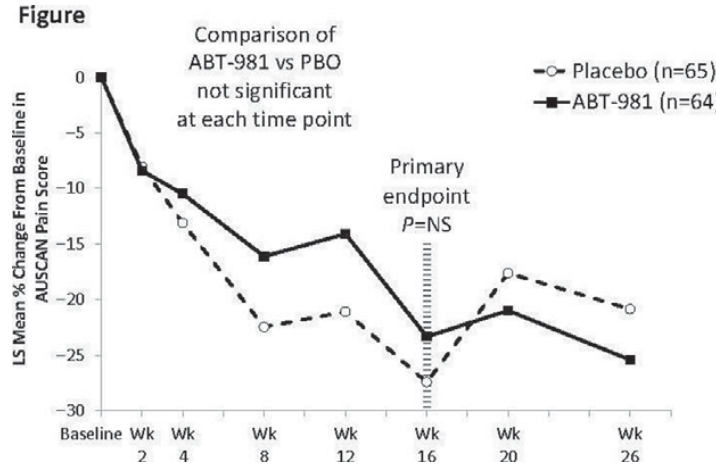

Boehringer Ingelheim, Celgene, Daiichi, Eli-Lilly, Galapagos, Gilead, Janssen, Merck, Novartis, Pfizer, Regeneron, Roche, Sanofi, UCB, Employee of: Director of Imaging Rheumatology bv., J. Medema Shareholder of: AbbVie, Employee of: AbbVie, M. Levesque Shareholder of: AbbVie, Employee of: AbbVie

DOI: 10.1136/annrheumdis-2017-eular.4947

\section{OP0169 EARLY OSTEOPHYTES DETECTED BY MRI ARE ASSOCIATED WITH CHANGES IN KNEE PAIN AND STRUCTURES IN OLDER ADULTS: A POPULATION-BASED COHORT STUDY}

Z. Zhu ${ }^{1}$, L.L. Laslett ${ }^{1}$, W. Han ${ }^{1}$, B. Antony ${ }^{1}$, F. Cicuttini ${ }^{2}$, G. Jones ${ }^{3}$, C. Ding ${ }^{3}$. ${ }_{1}^{1} 12779$, Hobart; ${ }^{2}$ Department of Epidemiology and Preventive Medicine, Monash University, Melbourne; ${ }^{3}$ Musculoskeletal Unit, 12779, Hobart, Australia

Background: Early stage of osteophyte (OP) formations are hard to be detected by radiography, but can be detected by magnetic resonance imaging (MRI). Their subsequent developments on structural and clinical abnormalities are still unknown.

Objectives: To describe the prevalence of early osteophytes (OPs) that were detected by magnetic resonance imaging (MRI) but not by X-ray in older adults and to evaluate the longitudinal associations with knee pain and structural changes.

Methods: 837 participants (mean age 62 years, 50\% female) were randomly selected from local community at baseline. T1- or T2-weighted fat suppressed MRI was used to assess knee OPs, cartilage volume, cartilage defects and bone marrow lesions (BMLs) at baseline and after 2.6 years. Knee pain was assessed by self-administered Western Ontario and McMaster Osteoarthritis (WOMAC) Index questionnaire at baseline and after 5 years. X-ray-detected OPs were assessed at baseline using the Osteoarthritis Research Society International atlas. OPs detected only by MRI but not by standard X-ray were defined as early OPs. OPs detected by both MRI and X-ray were defined as definite OPs.

Results: The prevalence of early OPs was $75 \%$ while the prevalence of definite OPs was $10 \%$ in total knee at baseline. Compared with participants without any OPs, participants with early OPs and with definite OPs had greater cartilage volume loss and increased cartilage defects and BMLs over 2.6 years. Presence of early medial tibiofemoral OPs predicted decreases in total knee pain over 5 years, while definite OPs predicted increases in total knee pain, after adjustment for relevant covariates.

Table 1. Longitudinal associations of OP phenotype status and WOMAC knee pain changes

\begin{tabular}{|c|c|c|}
\hline & Adjusted $^{*} \beta(95 \% \mathrm{Cl})$ & Adjusted $^{\star *} \beta(95 \% \mathrm{Cl})$ \\
\hline \multicolumn{3}{|l|}{ Total } \\
\hline No OPs (n=103) & Ref. & Ref. \\
\hline Early OPs $(n=481)$ & $-0.23(-1.33,0.88)$ & $-0.28(-1.40,0.84)$ \\
\hline Definite OPs $(n=62)$ & $2.20(0.51,3.89)$ & $1.96(0.17,3.76)$ \\
\hline \multicolumn{3}{|l|}{ Medial tibiofemoral } \\
\hline No OPs $(n=447)$ & Ref. & Ref. \\
\hline Early OPs $(n=155)$ & $-1.25(-2.2,-0.30)$ & $-1.51(-2.50,-0.52)$ \\
\hline Definite OPs $(n=43)$ & $2.91(1.21,4.60)$ & $2.54(0.74,4.35)$ \\
\hline \multicolumn{3}{|l|}{ Lateral tibiofemoral } \\
\hline No OPs $(n=287)$ & Ref. & Ref. \\
\hline Early OPs (n=332) & $0.12(-0.70,0.94)$ & $-0.05(-0.91,0.81)$ \\
\hline Definite OPs $(n=27)$ & $1.08(-1.11,3.27)$ & $0.35(-1.95,2.66)$ \\
\hline
\end{tabular}
BMI. **Further adjusted for BMLs and cartilage defects.

Conclusions: Although early OPs are associated with knee abnormal structural changes, they predict decreases in knee pain over time suggesting an adaptive response.

References:

[1] Centers for Disease C, Prevention. Public health and aging: projected prevalence of self-reported arthritis or chronic joint symptoms among persons aged >65 years-United States, 2005-2030. MMWR Morb Mortal Wkly Rep 2003; 52: 489-491.

Acknowledgements: The authors thank the participants who made this study possible, and acknowledge the role of the staff and volunteers in collecting the data, particularly research nurses Boon $\mathrm{C}$ and Boon P. Warren R assessed MRIs and Dr Srikanth $\mathrm{V}$ and $\mathrm{Dr}$ Cooley $\mathrm{H}$ assessed radiographs. 